Bangladesh Journal of Neuroscience 2014; Vol. 30 (2): 96-103

\title{
Relationship between Blood Lipids, Lipoproteins and Ischemic Stroke
}

\author{
MD. REZAUL KARIM KHAN ${ }^{1}$, AKM ANWARULLAH ${ }^{1}$, MD. SHAFIQUS SALEHEEN ${ }^{2}$, \\ SK MAHBUB ALAM ${ }^{3}$, MD. RAFIQUL ISLAM ${ }^{1}$, SYEDA TABASSUM ALAM ${ }^{4}$
}

\begin{abstract}
:
Objective: To find out the relationship of different lipids, lipoproteins and ischemic stroke patients in Bangladesh. Methodology: This case control study was conducted among the patients having ischemic stroke who were admitted in Department of Neurology, Bangabandhu Sheikh Mujib Medical University (BSMMU), Dhaka, Bangladesh during the period from July, 1997 to June, 1999 and age, sex matched apparently healthy volunteers. Sixty ischemic stroke patients confirmed by CT scan of brain and sixty age and sex matched apparently healthy volunteers were enrolled as controls. 12 hours fasting lipid profile (Total cholesterol, LDL-cholesterol, HDLcholesterol and Triglyceride) was done for both ischemic stroke patients and healthy volunteers for comparison. The students (unpaired) $t$ test was used to compare group means for lipids and lipoproteins. Chi square test, odds ratio with confidence interval were done to evaluate differences between the groups for other variables. $P<0.05$ was considered as minimum level of significance. Result: The mean age ( $\pm S D$ ) of the patients and controls were $58.45 \pm 10.12$ and $59.40 \pm 10.41$ years respectively and 44 (73.3\%) were male and 16 (26.7\%) were female and male-female ratio was 2.75:1 in both cases and controls. Total cholesterol (Means) was 201.62 $\pm 5.52 \mathrm{mg} / \mathrm{dl}$ and $169.13 \pm 3.49 \mathrm{mg} / \mathrm{dl}$ in cases and controls respectively $(P<0.001)$. HDL cholesterol (Means) was $38.36 \pm 0.81 \mathrm{mg} / \mathrm{dl}$ and $44.03 \pm 0.84 \mathrm{mg} / \mathrm{dl}$ in cases and controls respectively $(P<0.001)$. LDL cholesterol (Mean $\pm S E)$ in ischemic stroke patients and controls were $125.45 \pm 4.63 \mathrm{mg} / \mathrm{dl}$ and $96.40 \pm 3.23 \mathrm{mg} / \mathrm{dl}$ respectively $(P<0.001)$. Triglyceride (Mean \pm SE) in cases and controls were $188.50 \pm 9.35 \mathrm{mg} / \mathrm{dl}$ and $142.85 \pm 4.72 \mathrm{mg} / \mathrm{dl}$ respectively $(P<0.001)$. Conclusion: This case-control study showed significant differences of serum lipids and lipoproteins (Total cholesterol, HDL cholesterol, LDL cholesterol and triglyceride) in ischemic stroke patients than the controls in our community.
\end{abstract}

Introduction:

Stroke is the third commonest cause of death after ischemic heart disease and cancer in developed countries and is responsible for a large proportion of physical disability ${ }^{1}$. WHO defined stroke as rapidly developing clinical signs of focal (at times global) disturbance of cerebral function, lasting more than 24 hours or leading to death with no apparent cause other than that of vascular origin $^{2}$.The main types of stroke and their occurrences are: Ischemic stroke $85 \%$ \& Hemorrhagic stroke $15 \%{ }^{3}$. The ischemic stroke is the resultant effect of the occlusion of the cerebral blood vessels by thrombus or embolus, nonatheromatous diseases of the vessel wall, e.g. collagen diseases and vasculitis, diseases of blood e.g. coagulopathies and haemoglobinopathies, decreased cerebral perfusion due to shock of any cause and cardiac dysrhythmias which leads to infarction of brain 4 .

1. Professor, Department of Neurology, Bangabandhu Sheikh Mujib Medical University, Shahbag, Dhaka.

2. MD (Neurology) Student, Bangabandhu Sheikh Mujib Medical University, Shahbag, Dhaka.

3. Associate Profwessor, Department of Neurology, Bangabandhu Sheikh Mujib Medical University, Shahbag, Dhaka.

4. Associate Professor, Paediatric Neurology, Bangabandhu Sheikh Mujib Medical University, Shahbag, Dhaka. 
Atherosclerosis is a disease primarily of the elastic arteries (e.g. aorta, carotid and iliac arteries), large and medium sized muscular arteries (e.g. coronary and popliteal arteries). But any arteries may be affected and is a progressive disease that starts in childhood ${ }^{5}$. The basic lesion- the atheroma or fibrofatty plaque consists of a raised focal plque within the intima, having a core of lipid (mainly cholesterol and cholesterol esters) and a covering fibrous cap. Atheromas are sparsely distributed at first but as the disease advances, they become more and more numerous, sometimes covering the entire circumference of severely affected arteries. As the plaque increase in size, they progressively encroach on the lumen of the artery as well as the subjacent media. Consequently, in small ateries, thrombus are occlusive compromising blood flow to distal organs and causing ischemic injury, but in large arteries they are destructive weakening the affected vessel wall, causing aneurysm or rupture or favouring thrombosis. Moreover, extensive atheromas are friable often yields emboli of their grumous contents into the distal circulation (atheroemboli).

Epidemiological studies indicate that there are several risk factors of atherosclerosis e.g. age, sex, diet, hypertension, diabetes mellitus, hypercholesterolemia, cigarette smoking, obesity, physical inactivity, type A personality, high carbohydrate intake ${ }^{5}$.Among the risk factors, hypercholesterolaemia and hypertriglyceridemia are important. The biologically important lipids are the fatty acids and their derivatives, the neutral fats (triglyceride), the phospholipids and related compounds and the sterols (cholesterol andtheir derivatives). The lipids are hydrophobic substances and cannot circulate in the plasma in free form. The free fatty acids are bounded to albumin whereas, cholesterol, phospholipids, triglycerides are transported in the form of lipoprotein complexes. There are six families of lipoprotein, e.g. chylomicrones, chylomicron remnants, very low density lipoprotein (VLDL), intermediate density lipoprotein (IDL), low density lipoprotein (LDL) and high density lipoprotein (HDL) 6 .

A subject of great interest is the role of the cholesterol in the aetiology and course of atherosclerosis. It is characterized by infiltration of cholesterol and appearance of foam cells in the intima and growth factors that produces proliferative lesions. The normal range for plasma cholesterol is said to be $120-200 \mathrm{mg} / \mathrm{dl}$, but it is now clear that there is tight, positive correlation between the death rate from ischaemic heart disease and plasma cholesterol levels above $180 \mathrm{mg} / \mathrm{dl}$. Furthermore it is now clear that plasma cholesterol by diet and drugs slows and even reverse the progression of atherosclerotic lesions and the complications they cause $^{7}$.Plasma cholesterol levels are elevated by diet rich in cholesterol and saturated fats, such as egg yolk, animal fats and butter.

There is no doubt that increasing levels of total plasma cholesterol and LDL-cholesterol and to, a lesser extent, decreasing levels of HDL-cholesterol, are strong risk factors for coronary heart disease ${ }^{8,9}$, whereas blood triglyceride levels are not predictive $^{10}$.The relationship between cholesterol or lipid fractions and stroke is less clear-cut but there is almost certainly association ${ }^{11}$.

In Bangladeshi population, there are studies which showhypercholesterolemia as a risk factor for stroke ${ }^{12,13}$ and thepresence of hypercholesterolemia in higher and middle class Bangladeshi population ${ }^{14}$.

This study may reflect the prevalance of hyperlipidemia in normal Bangladeshi population and ischaemic stroke patient where the food habit is different from Western population. Therefore, the goal of this study was designed to determine the relationship between blood lipids, lipoproteins and ischaemic stroke.

\section{Materials and Methods:}

This case-control study carried out in the Department of Neurology, Bangabandhu Sheikh Mujib Medical University (BSMMU), Dhaka, Bangladesh during the period from July, 1997 to June, 1999. Men and women aged between 35 to 79 years who concord with the definition of cases and controls were eligible to enter into the study. Sixty ischemic stroke patients confirmed by CT scan of brain and sixty age and sex matched apperently healthy volunteers were enrolled as controls. Patients and guardians of the subjects were explained fully about the nature, benefit and the risk of the study. Prior consent from the subjects or from their attendants were taken for the same. The details 
information about the present illness including mode of onset, subsequent course, associated features and duratinof illness were noted in a printed proforma. Age, sex, occupation, known hypertension, smoking habit, ischaemic heart disease, family history of stroke, past history of stroke/TIA were also recorded. Through general, systemic and neurological examination including heigh, weight, radial and peripheral pulses, blood pressure, carotid bruit, heart sound, xanthelesma, tendon xanthoma, arcus lipidus if present were also recorded in a printd proforma. All necessary investigations including complete blood count, platelet count, urine analysis, 12 hours fasting blood glucose and 2 hours after breakfast, 12 hour fasting lipid profile ( Total cholesterol, LDL-cholesterol, HDLcholesterol and Triglyceride), X-ray chest P/A view, ECG, echocardiography and CT scan of brain were done for each and every patient. Through history and clinicl examination, urine analysis, fasting blood sugar and fasting lipid profile were done for each control. Appropriate statistical analysis like mean, standard deviation and standard error were done. The students's (unpaired) t test was used to compare group means for lipids and lipoproteins. Chi square test, odds ratio with confidence interval were done to evaluate differences between the groups for other variables. $P<0.05$ was considered as minimum level of significance.

Results:

The mean age $( \pm S D)$ age of the patients and controls were $58.45 \pm 10.12$ and $59.40 \pm 10.41$ years respectively. 44 (73.3\%) were male and $16(26.7 \%)$ were female and male- female ratio was $2.75: 1$ in both cases and controls. $55 \%$ and $33 \%$ of cases and controls were smokers. Odds ratio (2.44) and Chi square test showed significant result $(P<0.02)$. $33 \%$ and $13 \%$ of cases and controls were diabetic.Odds ratio (3.25) and Chi square test were significant $(P<0.02)$. In this study hypertension was a very importanr risk factor for ischaemic stroke. $55 \%$ of cases and $22 \%$ of controls were hypertensive.Odds ratio (4.41) and Chi square test were highly significant $(P<0.001) .32 \%$ of cases and $12 \%$ of controls had heart disease. Odds ratio (3.5) and Chi square test were significant $(P<0.01)$. In this study case-control study, family history of stroke was not a significant risk factor for ischaemic stroke. $23 \%$ of cases and $17 \%$ of controls had family history of stroke.Odds ratio (1.52) and Chi square were insignificant $(P>0.50)$. Increased $\mathrm{BMI}$ was $28 \%$ in cases and $8 \%$ of controls. Odds ratio (4.34) and Chi square test were significant $(P<0.01)$. Total cholesterol (Mean $\pm S E$ ) was $201.62 \pm 5.52 \mathrm{mg} / \mathrm{dl}$ and $169.13 \pm 3.49 \mathrm{mg} / \mathrm{dl}$ in cases and controls respectively. Unpaired t test showed significant result $(\mathrm{P}<0.001)$. HDL cholesterol (Mean \pm SE) was $38.36 \pm 0.81 \mathrm{mg} / \mathrm{dl}$ and $44.03 \pm 0.84 \mathrm{mg} / \mathrm{dl}$ in cases and controls respectively. Unpaired t test showed significant result $(P<0.001)$.LDL cholesterol (Mean \pm SE) in ischaemic stroke patients and controls were $125.45 \pm 4.63 \mathrm{mg} / \mathrm{dl}$ and $96.40 \pm 3.23$ $\mathrm{mg} / \mathrm{dl}$ respectively. Unpaired $\mathrm{t}$ test was significant $(P<0.001)$. Triglyceride (Mean $\pm S E)$ in cases and controls were $188.50 \pm 9.35 \mathrm{mg} / \mathrm{dl}$ and $142.85 \pm 4.72$ $\mathrm{mg} / \mathrm{dl}$ respectively. Unpaired $\mathrm{t}$ test was significant $(P<0.001)$.

Table-I

Age and Sex distribution of ischaemic stroke patients and controls

\begin{tabular}{lcccc}
\hline Age group(in years) & \multicolumn{2}{c}{ Cases } & \multicolumn{2}{c}{ Controls } \\
& Malen (\%) & Femalen (\%) & Malen (\%) & Femalen (\%) \\
\hline $35-39$ & $1(1.7)$ & $1(1.7)$ & $1(1.7)$ & $1(1.7)$ \\
$40-44$ & $1(1.7)$ & $1(1.7)$ & $1(1.7)$ & $1(1.7)$ \\
$45-49$ & $6(10)$ & $1(1.7)$ & $6(10)$ & $1(1.7)$ \\
$50-54$ & $10(16.7)$ & $1(1.7)$ & $10(16.7)$ & $1(1.7)$ \\
$55-59$ & $3(5)$ & $2(3.3)$ & $3(5)$ & $2(3.3)$ \\
$60-64$ & $5(8.2)$ & $5(8.2)$ & $5(8.2)$ & $5(8.2)$ \\
$65-69$ & $9(15)$ & $1(1.7)$ & $9(15)$ & $1(1.7)$ \\
$70-74$ & $8(13.3)$ & $3(5)$ & $8(13.3)$ & $3(5)$ \\
$75-79$ & $1(1.7)$ & $1(1.7)$ & $1(1.7)$ & $1(1.7)$ \\
\hline
\end{tabular}


Table-II

Distribution of the study groups according to risk factors

\begin{tabular}{lcccc}
\hline Risk Factor & & Casesn (\%) & Controln (\%) & P value \\
\hline Smoker & Yes & $33(55 \%)$ & $20(33 \%)$ & $<0.02^{\mathrm{s}}$ \\
\multirow{4}{*}{ Diabetes Mellitus } & No & $27(45 \%)$ & $40(67 \%)$ & $<0.02^{\mathrm{s}}$ \\
\multirow{2}{*}{ Hypertension } & Yes & $20(33 \%)$ & $8(13 \%)$ & $<0.001^{\mathrm{s}}$ \\
& No & $40(67 \%)$ & $52(87 \%)$ & $<0.01^{\mathrm{s}}$ \\
IHD & Yes & $33(55 \%)$ & $27(45 \%)$ & $>0.50^{\text {ns }}$ \\
\multirow{2}{*}{ Family History } & No & $13(22 \%)$ & $47(78 \%)$ & $<0.01^{\mathrm{s}}$ \\
& Yes & $19(32 \%)$ & $41(68 \%)$ & \\
BMI & No & $7(12 \%)$ & $53(88 \%)$ & \\
& Yes & $14(23 \%)$ & $46(77 \%)$ & \\
\hline
\end{tabular}

$\mathrm{s}=$ significant; $\mathrm{ns}=$ notsignificant; $\mathrm{P}$ value reached from chi square test.

Table-III

Distribution of the study groups according to Lipid profile

\begin{tabular}{lccl}
\hline Lipid & Cases(Mean \pm SE) & Controls(Mean $\pm S E)$ & P value \\
\hline Total Cholesterol & $201.62 \pm 5.52$ & $169.13 \pm 3.49$ & $<0.001^{\mathrm{s}}$ \\
HDL Cholesterol & $38.36 \pm 0.81$ & $44.03 \pm 0.84$ & $<0.001^{\mathrm{s}}$ \\
LDL Cholesterol & $125.45 \pm 4.63$ & $96.40 \pm 3.23$ & $<0.001^{\mathrm{s}}$ \\
Triglyceride & $188.50 \pm 9.35$ & $142.85 \pm 4.72$ & $<0.001^{\mathrm{s}}$ \\
\hline
\end{tabular}

$\mathrm{s}=$ significant; $\mathrm{SE}=$ Standard error; $\mathrm{P}$ value reached from chi square test.

Discussion:

This study was carried out in the department of Neurology, BSMMU, Dhaka during the period from July, 1997 to June, 1999 to observe the role of lipids and lipoproteins (Total cholesterol, LDL-cholesterol, HDL-cholesterol and Triglyceride) in ischaemic stroke patients. The study subjects were sixty ischaemic stroke patients with age and sex matched sixty apparently healthy volunteers who gave blood sample for analysis.

In this study, the age range was 35 to 79 years with mean $\pm S D 59.45 \pm 10.41$ years in controls. The male female ratio 2.75 in both cases and controls. Since matching was done for age, sex, the age and sex distribution for cases and controls were very similar.

The majority of patients were in $7^{\text {th }}$ decade $20(33 \%)$ and $6^{\text {th }}$ decade $16(27 \%)$. Next common age group were $8^{\text {th }}$ decade $13(21 \%)$ and $5^{\text {th }}$ decade $9(15 \%)$. Mohammad et $\mathrm{al}^{15}$ in their study of cerebral thombosis and risk factors found $41 \%$ in $5^{\text {th }}$ decade and $16 \%$ in $6^{\text {th }}$ decades. Increasing age is the strongest risk factor for cerebral infarction, primary intracerebral haemorrhage and subarachnoid haemorrhage ${ }^{16}$ and transient ischaemic attack ${ }^{17}$. Mathur et $\mathrm{al}^{18}$ in their study of correlation of the extent of severity of atherosclerosis in the coronary and cerebral arteries observed atherosclerotic lesions in coronary arteries in earlier age groups and cerebral arteries in older age groups.

There is a small male excess of strokes ${ }^{19}$ and most strokes are ischaemic in nature $(80 \%)$ and this differences are mostly due to male sex as ischaemic stroke occurs less in premenopausal women due to female hormonal protection. In this study, male- 
female ratio $2.75: 1$, which is a bit higher than the western studies ${ }^{20,21}$. This male excess in our country is due to the fact that male beds are more than the females in this hospital as well as the culture that females are not given proper attention by the family. In this present study $55 \%$ of cases and $33 \%$ of controls were smoker. Odds ratio and $\mathrm{X}^{2}$ test shows significant result $(P<0.02)$.

Smoking is firmly established as a risk factor in diseases caused by atherosclerosis 5 .Cigarette smoking may precipitate clinical events through association with high fribinogen levels, haemoglobin concentration and myocardical oxygen supply ${ }^{22}$. Fogelholm et $\mathrm{al}^{23}$ in their study of ischaemic cerebrovascular disease in the young adult found $74 \%$ were smoker. Mohammad et al ${ }^{15}$ found $50 \%$ of cerebral thrombosis parients were smoker in their study of risk factors. Quizibash et al ${ }^{11}$ in a study of ischaemic stroke and TIA found $75 \%$ cases and $23 \%$ in control as smoker. Our findings are also consistent with other studies ${ }^{24,25}$.

In this present series $33 \%$ cases were diabetic Vs $13 \%$ of controls. Odds ratio, $X^{2}$ with Yates' correction was significant $(P<0.02)$. Diabetes mellitus has long been recogniswd as a risk factor for vascular diseases in general. Atherosclerosis begins to appear in most diabetics within few years of onset.Atherosclerosis may result in arterial narrowing or occlusions with ischaemic injuries to organs. In brain, it produces ischaemic strokes. The susceptibility of the diabetic to atherosclerosis is due to several factors. Hyperlipidaemia occurs in one third to one-half of patients, but even those with normal lipids have severe atherosclerosis. Diabetes have increased platelet adhesiveness and response to aggregating agents ${ }^{26}$. Aronow et $\mathrm{al}^{27}$ in their 3 years follow up study of risk factors correlated with atherothombotic brain infarct in 708 elderly patients found diabetes mellitus as significant risk factor $(P<0.001)$. Rothrock et $a^{28}$ in the analysis of ischaemic stroke found diabetes mellitus in $23 \%$ cases.

This study reveals $55 \%$ of cases and $22 \%$ of controls were hypertensive. Odd ratio and $\mathrm{X}^{2}$ test shows a significant result $(P<0.001)$. Hypertension is a strong risk factor for stroke in all the main pathological types $^{29}$. It increases stroke risk by increasing the extent and severity of atheroma ${ }^{30,31}$. Hypertension also induces microvascular disease in the small penetrating arteries within the brain ${ }^{32}$.

Quizibash et al ${ }^{11}$ in their study of minor stroke \& TIA found $51 \%$ and $29 \%$ as hypertensive in the patients and controls respectively with a significant difference having $P$ value $<0.001$. Sandercock et al $^{33}$ intheir study of predisposing factors for cerebral infarction found hypertension in $52 \%$ of cases. Our study also correlates with the findings of Mohammad et $\mathrm{al}^{15}$. Several studies in home and abroad indicate that hypertension is a strong determinant of ischaemic stroke ${ }^{34,35,36,37}$.

Present study shows $32 \%$ of patients and $12 \%$ of controls had heart disease. Odds ratio and $X^{2}$ test with Yates' correction shows that it is a risk factor for ischaemic stroke $(P<0.01)$. Independent of age, coronary heart disease (i.e. angina or myocardial infarction) is clearly associated with ischaemic stroke. The evidence comes from postmortem ${ }^{38,39}$, case-control $^{40}$ and cohort studies ${ }^{20}$. The most frequent potential of cardiac sources of embolism to the brain is atrial fibrillation, usually non-rheumatic in developed countries ${ }^{33}$. Both non-rheumatic and rheumatic atrial fibrillation have been associated with ischaemic stroke ${ }^{37,40}$. Some of the association must be coincidental because atrial fibrillation can be caused by coronary and hypertensive heart disease ${ }^{41}$. Our study also correlates with the findings of Sandercock et $\mathrm{al}^{33}$ in their study of predisposinf factor for cerebral infarction found ischaemic heart disease in $38 \%$ cases.

In this study $23 \%$ cases had positive family history of stroke compared with control (17\%). Odds ratio and $X^{2}$ test shows insignificant result $(P>0.50)$. The genetic predisposition to cerebrovascular disease is presumably multifactorial, the inheritence of hypertension being itselfmultifactorial. However an interesting component of the genetic load has been uncovered recently e.g. homocystinuria is prone to premature atheromatous vascular disease. One type of cerebral amyloidosis, hereditary cystatin C amyloid angiopathy, is transmitted as an autosomal dominant. This disorder produces intracerebral haemorrhage ${ }^{42}$. Our study correlates with the study 
of Kubota et $\mathrm{al}^{43}$ in a case control study of stroke patients found family history of stroke as nonsignificant risk factor (odds ratio 1.41) in ischaemic stroke.

Increased BMI was present in $28 \%$ of cases and $8 \%$ of controls. Odds ratio and $X^{2}$ test after Yates' correction was significant $(P<0.01)$. Obesity is a risk factor for cerebral infarction, probably through its association with Diabetes Mellitus, hypertension and alcohol consumption ${ }^{42}$. Aronow et $\mathrm{al}^{27}$ in their study of three year follow up of risk factors correlated with atherothrombotic brain infarction found obesity as an important risk factor $(P<0.005)$.

In this case-control study, the mean \pm SE of total cholesterol was $201.62 \pm 5.52 \mathrm{Vs} 169.13 \pm 3.49 \mathrm{mg} /$ $\mathrm{dl} ; \mathrm{HDL}=38.36 \pm 0.81 \mathrm{Vs} 44.03 \pm 0.84 \mathrm{mg} / \mathrm{dl}$; LDL cholesterol $125.45 \pm 4.63 \mathrm{Vs} 96.40 \pm 3.23 \mathrm{mg} / \mathrm{dl}$ and Triglyceride $188.50 \pm 9.35 \mathrm{Vs} 142.85 \pm 4.72 \mathrm{mg} / \mathrm{dl}$; in cases and controls respectively. All the results show statistically significant differences. A number of mechanisms have been potulated to account for the role of lipids in atherogenesis leading to IHD, ischaemic stroke and peripheral vascular diseases. Increased in plasma level of LDL or some component of hyperlipidemic serum may increase the rate of lipid penetration into artery wall. Local modification of LDL may render it more atherogenic. Hyperlipoproteinemia may directly alter endothelial cell function, without leading to denudation, through focal endothelial cell death, increased permeability or increased monocyte adhesion ${ }^{5}$. Our study correlates with the following studies. Randrup et al ${ }^{44}$ found significantly elevated plasma total cholesterol (220 mg/dl) and fasting Triglyceride (116 $\mathrm{mg} / \mathrm{dl}$ ) in apoplectic patients with total occlusion of a cerebral artery when compared with age and sex matched controls $(203 \mathrm{mg} / \mathrm{dl}$ and $100 \mathrm{mg} / \mathrm{dl}$, total cholesterol and triglyceride respectively).Duncan et $\mathrm{al}^{45}$ examined plasma cholesterol in endarterectomy candidates with angiographic evidence for stenosis at least one internel carotid atery compared with age and sex matched controls, cases had significantly higher total cholesterol (221 Vs 193 $\mathrm{mg} / \mathrm{dl}$ ). Fasting triglyceride were also significantly higher in cases, than in controls (157 Vs $129 \mathrm{mg} /$ dl). Iso et al ${ }^{46}$ intheir studydetected highr cholesterol level in ischaemic stroke and lower value in haemorrhagic stroke. Quizibash et al $^{11}$ in their study of TIA and minor stroke detected significantly higher total cholesterol, LDL cholesterol and lower value for HDL cholesterol than their age and sex matched controls and concluded total, HDL, LDLcholesterol are risk factors for ischaemic stroke. Salonen et al ${ }^{47}$ found positive association with serumcholesterol and TG level in their study of ischaemic stroke. Boutron et $\mathrm{al}^{48}$ in a study of cerebral infarct (61 Cases) and 31 TIA cases compared with matched controls and observed maximum increased of totalcholesterol, VLDL, LDL and triglyceride withdecrease in HDLcholesterol.

Controversies also exist regarding the role of lipids in ischaemic strokes. The negative results from case-control studies ${ }^{25,49,50}$ may have been derived from the influence of cerebrovascular disease on serum lipid concentrations due to physical inactivity, poor nutrition or changes in the diet.

\section{Conclusion:}

This case-control study showed significant differences of serum lipids and lipoproteins (Totalcholesterol, HDLcholesterol, LDLcholesterol and triglyceride) in cases and controls in our community. They are important risk factors for ischaemic stroke. Further community based prospective cohort study with large sample size is required to establish its role as risk factor for ischaemic stroke to take preventiveand curative measures in our country.

\section{References:}

1. Allen CMC, Lueck CJ. Diseases of the nervous system. In: Haslette C, Chilvers ER, Hunter JAA, Boon NA, editors. Davidsons's principles and practice of medicine. $18^{\text {th }}$ edition. London: Churchill living stone; 1999. p.923-1024.

2. Hatano S. Experience from a multicentre stroke register- a preliminary report. Bulletin of World Health Organisation 1976; 54(5): 541-53.

3. Brown MM. Cerebrovascular disease : Epidemiology, history, examination and differential diagnosis. Medicine International 1996; 10(34): 35-41. 
4. Lindsay KW, Bone I, Callander R, editors. Neurology and Neurosurgery Illustrated. $3^{\text {rd }}$ ed. London:Churchill living stone 1999; 236-92.

5. Schoen FJ. Blood vessels. In: Cotran RS, Kumar V, Robbins SL, Schoen FJ, editors. Robbins Pathologic basis of disease. $5^{\text {th }}$ edition. Philadelphia: WB Saunders company; 1994. p. 467-16.

6. Ganong WF. Review of medical physiology. $19^{\text {th }}$ ed.New York: Prentice-Hall International; 1999. p. 286-97.

7. Peto R, Yusuf S, Collins R. Cholesterol level trials in their epidemiological context. Circulation 1985; 72 (Suppl. III): 451-451.

8. Martin MJ, Hulley SB, Browner WS< Kuller LH, Wentworth D. Serum cholesterol, Blood pressure and mortality: Implications from a cohort of 31662 men. Lancet 1986;25;2(8513): 933-6.

9. Pocock SJ, Sharper AG, Phillips AN. Concentrations of High density lipoprotein cholesterol, triglyceride and total cholesterol in ischaemic heart disease. BMJ 1989;15; 298(6679):998-1002.

10. Hulley SB, Rosenman RH, Bawol RD, Brand RJ. Epidemology as a guide to clinical decisions: The association between triglyceride and coronary heart disease. NEJM 1980;19; 302(25):1383-9.

11. Quizibash N, Jones L, Warlow C, Mann J. Fibrinogen and lipid concentrations as risk factors of transient ischaemic attacks and minor ischaemic stroke. BMJ 1991;14; 303(6803):605-9.

12. ${ }^{* * *}$ Anwarullah AKM, Habib M,Mohammad QD, Ahmmed S, Nahar S. Review of risk factors for stroke- study of 100 cases. Bangladesh Journal of Neuroscience 1993; 9:11-20.

13. Hayee MA. Relationship of stress to stroke [thesis]. Dhaka: Dhaka University; 1999.

14. Chowdhury S, Huda AMS. Study on serum cholesterol level inapparently health persons of different socio-economic groups in Dhaka. Bangladesh Medical Journal 1979; 7:65-73.

15. Mohammad QD, Mannan MA, Fakir $\mathrm{NH}$, Rahman HZ, Quraishi FA, Begum JA. Cerebral thrombosis and risk factors- Study of twelve
cases.Bangladesh Journal of Neuroscience 1987; 3(2):48-54.

16. Bamford J, Sandercock P, Jones L, Walow C. The natural history of lacunar infarction: The Oxfordshire community stroke project. Stroke 1987;18(3):545-51.

17. Dennis MS, Bamford JM, Sandercock PAG, Warlow CP. Comparison of risk factors and prognosis of transient ischaemic attack and minor ischaemic stroke. Stroke 1989; 20: 1494-99.

18. Mathur KS, Kashyap SK, Kumar V. Correlation of extent of severity of atherosclerosis in the coronary and cerebral arteries. Circulation 1963; 27:929-34.

19. Haberman S, Capildeo R, Rose FC. Sex differences in the incidence of cerebrovascular disease. Journal of Epidemiology and common health 1981; 35(1):45-50.

20. Kannel WB, Mcgee DL. Diabetes and cerebrovascular disease: The Framingham study. JAMA 1979; 241(19):2035-8.

21. Bonita R, Scagg R, Stewart A, Jackson R, Beaglehole R. Cigarette smoking and risk of premature stroke in men and women. BMJ 1986;5;293:(6538)6-8.

22. Mc Gill $\mathrm{H}$. The cardiovascular pathology of smoking. Am Heart J 1988; 115:250-7.

23. Fogelholm, Aho K. Ischaemic cerebrovascular disease in young adults. Acta Neurol Scan dinav 1973; 49: 415-27.

24. Donan G, Mc Neil JJ, Adena MA, Doyle AE, Malley HM, Neil GC. Smoking as risk factor for cerebral ischaemia. Lancet 1989; 16:2(8664) 643-7.

25. Sridharan R. Risk factor for ischaemic stroke: A case control analysis. Neuroepidemiology 1992; 11: 24-30.

26. Crawford J, Cortan RS. The pancreas. In: Cotran RS, Kumar V, Robins SL, Shoen FJ. Robbins Pathologic basis of diseases. $5^{\text {th }}$ edition. Philadelphia: WB Saunders company; 1994. p. 897-925.

27. Aronow WS, Gutstein H, Lee NH, Edwards $\mathrm{M}$. Three year follow up of risk factors correlated with new atherothmbrotic brain infarction in 708 elderly patients. Angiology 1988; 39(7):563-66. 
28. Rothrock JF, Lyden P, Brody ML, Alvez BT, Kelly N, Mayer J et al. An analysis of ischaemic stroke in an urban southern California population. Arch Intern Med 1993; 8:153(5): 619-24.

29. Warlow C. Disorder of the cerebral circulation. In: Walton J editor. Brain's disease of nervous system. $10^{\text {th }}$ edition. Oxford university press, 1993; 197-268.

30. Russel RWR. How does blood pressure cause stroke? Lancet, 1975; ii : 1283-5.

31. Homer D, Ingall TJ, Baker HL. Serum lipids and lipoproteins are less powerful predictors of extracranial artery atherosclerosis than the cigarette smoking and hypertension. Mayo Clinic Process 1991;66(3): 259-67.

32. Russel RWR. Observations on intracerebral aneurysms.Brain, 1963; 86: 425-442.

33. Sandercock PAG, Warlow CP, Jone SLN, Starkey IR. Predisposing factors for cerebral infarction: The Oxford shire community stroke project. BMJ. 1989;14:298(6666):75-80.

34. Haque A, Mannan MA, Rahman ZH. Prognosis of acute stroke. Bangladesh Journal of Neuroscience 1987; 3(2): 42-47.

35. Mannan MA, Khan SIMK, Haq A, Sarwar G, Alam F, MohiuddinG. Report of 172 neurological patients in hospital for neurological diseases (Dhaka).Bangladesh Journal of Neuroscience 1991; 7(2): 72-9.

36. Anwarullah AKM, Miah GA, Islam KN. Pattern of admission in the department of Neurology, IPGMR-A one year study.Bangladesh Journal of Neuroscience 1992;8: 17-23.

37. Wolf PA, Agastino D, Belanger AD, Kannel WB. Probability of stroke: A risk profile from the Framingham study. Stroke 1991;22(3):3128.

38. Kagan A. Atherosclerosis and myocardial lesions in subjects dying fresh cerebrovascular diseases. Bull. WHO 1976;53:597-600.

39. Stemmermann GN, Hyashi T, Resch JA. Risk factors related to ischaemic and haemorrhagic cerebrovascular disease at autopsy: The Honolulu Heart study. Stroke 1984; 15(1):23-8.
40. Friedman GD, Loveland DB, Ehrlich SP. Relationship of stroke to other cardiovascular disease. Circulation 1968,38(3):533-41.

41. Davies PH, Dambrosia JM, Shoenberg BS. Risk factor for ischaemic stroke: A prospective study in Rochester, Minnesota. Ann Neural. 1987;22(3):319-27.

42. Hopkins A, Clinical Neurology. Oxford university press 1993; 129-68.

43. Kubota M, Yumaura A, Ono J, Itani T, Tachi N, Ueda K et al. Is family history an independent risk factor for stroke? J Neurol Neurosurg Psychiatry 1997;62(1):66-70.

44. Randrup A, Pakkenberg H. Plasma triglycerideand cholesterol levels in cerebrovascular disease: Sex and angiographic differences. J Atheroscler Res 1967; 7(1):17-24.

45. Duncan GW, Lees RS, Ojemann RG, Davis SS. Concomitants of Atheroscleotic Carotid Artery Stenosis. Stroke 1977;8:665-69.

46. Iso $\mathrm{H}$, Jacobs Jr. Dr, Wentworth $\mathrm{D}$, Neaton JD, Cohen JD. Serum cholesterol levels and six years mortality from stroke in 350977 men screen for the multiple risk factor intervention trial.NEJM 1989;6:320(14):904-10.

47. Salonen JT, Puska P. Relation on serum cholesterol and triglycerides to the risk of acute myocardial infarction, cerebral stroke and deah in eastern Finnish male population. Int $\mathrm{J}$ Epidemiol 1983;12(1):26-31.

48. Boutron MC, Giround M, Gras P, Gambert P, Lallemant C, Milan C et al. Plasma lipoproteins in cortical infarction versus transient ischaemic attacks: A case control study. J Neurology 1993;240:133-38.

49. Robinson RW, Higano N, Cohen WD. Comparison of serum lipid levels in patients with cerebral thrombosis and in normal subjects. Ann Intern Med. 1963;59:180-85.

50. Rossner S, Kjellin KG, Mettinger KI, Siden A, Soderstrom CE. Dyslipoproteinemia in patients with ischaemic cerebrovascular disease. A study of stroke before the age of 55 years Atherosclerosis 1978;30:199-207. 